\title{
Symptoms of musculoskeletal disorders in stage rally drivers and co-drivers
}

\author{
N J Mansfield, J M Marshall
}

\begin{abstract}
Background-During stage rallying, musculoskeletal injuries may be provoked by the high magnitude of vibration and shock to which the driver and co-driver are exposed. Drivers and co-drivers experience similar exposure to whole body mechanical shocks and vibration but different exposure to hand/wrist stressors.

Objectives-To investigate by a questionnaire study the prevalence of symptoms of musculoskeletal injuries after rallying in 13 professional and 105 amateur stage rally competitors.
\end{abstract}

Methods-The self administered questionnaire investigated whole body and hand/wrist symptoms of musculoskeletal injury. It was loosely based on the Nordic design.

Results-91\% of participants who competed or tested for more than 10 days a year $(n=90)$ reported discomfort in at least one body area after rallying. Problems in the lumbar spine $(\mathbf{7 0 \%})$, cervical spine (54\%), shoulders $(47 \%)$, and thoracic spine $(36 \%)$ were the most common. There was a higher prevalence of cervical spine discomfort for co-drivers $(62 \%)$ than for drivers (46\%). Conversely, there was higher prevalence of discomfort in the hands and wrists for drivers $(32 \%)$ than co-drivers $(9 \%)$. The prevalence of low back pain in rally participants is higher than that generally reported for workers exposed to whole body vibration. The prevalence of discomfort in the hand and wrist for rally drivers is similar to that previously reported for Formula 1 drivers. Conclusions-Most stage rally drivers and co-drivers report symptoms of musculoskeletal injury. It is logical to relate the high prevalence of symptoms of injury to the extreme environment of the rally car. (Br F Sports Med 2001;35:314-320)

Keywords: musculoskeletal injury; vibration; rally car; motor sport

Department of Human

Sciences,

Loughborough

University,

Loughborough,

Leicestershire

LE11 3TU, UK

N J Mansfield

J M Marshall

Correspondence to:

Dr Mansfield

n.j.mansfield@1boro.ac.uk

Accepted 5 July 2001
Musculoskeletal disorders have previously been studied in the context of occupational health and work related disorders. One focus has been on those employed as off-road vehicle drivers who have a high prevalence of back pain compared with control groups. Factors contributing to the prevalence of musculoskeletal disorders include poor posture and exposure to vibration and mechanical shocks. Amateur and professional competitors in motorsport are also exposed to high levels of vibration and shock and therefore may also be expected to show a high incidence of symptoms of musculoskeletal disorders.

Previous studies have shown a high prevalence of wrist injury and back pain for professional Formula 1 (F1) and rally drivers. Fourteen of the $22 \mathrm{~F} 1$ drivers (64\%) at the 1998 French Grand Prix reported upper extremity disorders, ${ }^{1}$ compared with a $25 \%$ incidence of wrist and hand injuries in the general sporting population. ${ }^{2}$ Furthermore, all drivers who participated before 1991 reported irritation to the palm of the right hand from use of a gear change lever. These symptoms were eliminated by the use of semiautomatic gear change levers mounted behind the steering wheel, introduced since the 1991 season. Chronic exposure to vibration has also been suggested as a cause of back pain for F1 drivers. ${ }^{3}$ The incidence and severity of back pain for F1 drivers decreased significantly between 1982 and 1983 because a rule change forced a reduction in the stiffness of suspension elements in F1 cars, thereby providing some degree of isolation from vibration. However, although the incidence decreased, most drivers in the 1983 season still reported pain in the cervical and lumbar spine.

Back pain has also been reported for a small population of rally drivers. Videman et $a l^{4}$ investigated pathological changes to the lumbar spine for rally participants using magnetic resonance imaging (MRI) analysis. ${ }^{4}$ Of 18 "top" rally drivers and co-drivers, $89 \%$ reported low back pain during the previous 12 months, compared with $79 \%$ in a control group $(n=14)$. Back pain for rally drivers also tended to be more common and more intense. In contrast with the authors' expectations, the MRI data did not show spinal degeneration for the rally drivers. Other pathological studies using MRI or radiography have also failed to find evidence of spinal degradation, except in the most severe environments, ${ }^{56}$ despite reports of back pain.

Previous studies of symptoms of musculoskeletal disorders have focused on professional drivers and have been limited to small populations. This paper reports a study designed to increase the volume of raw data on the types of musculoskeletal symptoms experienced by rally drivers and co-drivers by expanding the cohort to include both professionals and amateurs. The study was restricted to participants in stage rallies - that is, time trials that take place on closed roads where competitors are not required to obey speed limits-and excluded those who compete in navigation rallies only-that is, timed navigation competitions that take place on public roads where competitors are required to obey local traffic laws. It 


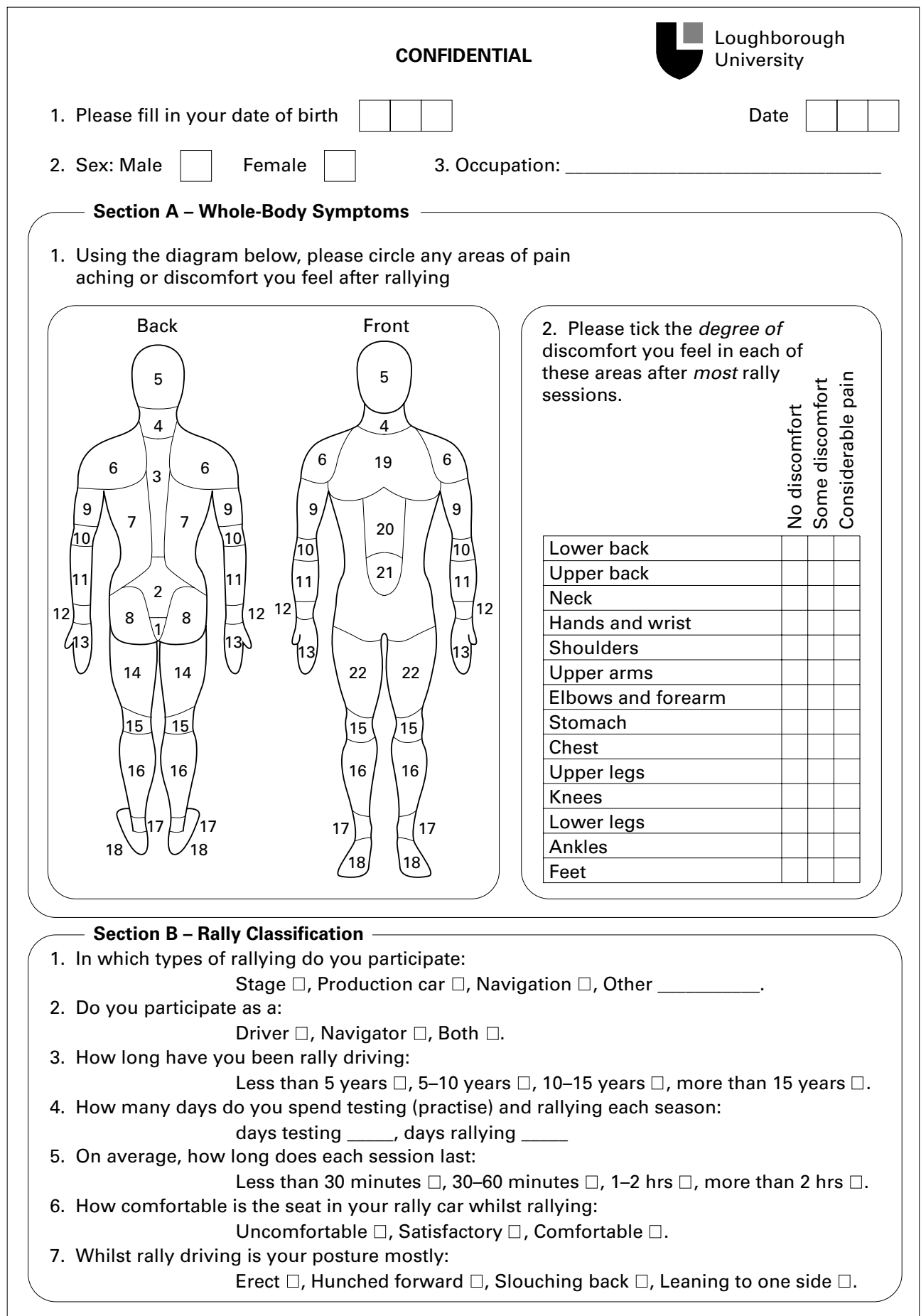

Figure 1 Questionnaire given to rally drivers and co-drivers about musculoskeletal symptoms after a competition.

was hypothesised that all rally participants would show a prevalence of whole body symptoms similar to those previously reported for rally and F1 drivers and that there would be no difference between the prevalence for drivers and co-drivers. Similarly, it was hypothesised that the prevalence of problems of the hand and wrist would be would similar in rally drivers to F1 drivers, but that co-drivers would report fewer symptoms.

\section{Methods}

A cross sectional, independent measures design was used to investigate the incidence and degree of musculoskeletal discomfort experienced by rally participants in the 2000 season. The study used a self administered questionnaire which drew inferences from the Nordic Musculoskeletal Questionnaire, ${ }^{7}$ the protocol of Magnusson et $a l^{\beta}$ for epidemiological studies, and the UK Medical Research Council (MRC) self administered questionnaire for assessing vibration injuries to the hand/arm and whole body. ${ }^{9}$ Despite possible benefits of using standardised methods, the prohibitive length of previously used questionnaires was considered unacceptable for this study. It was 


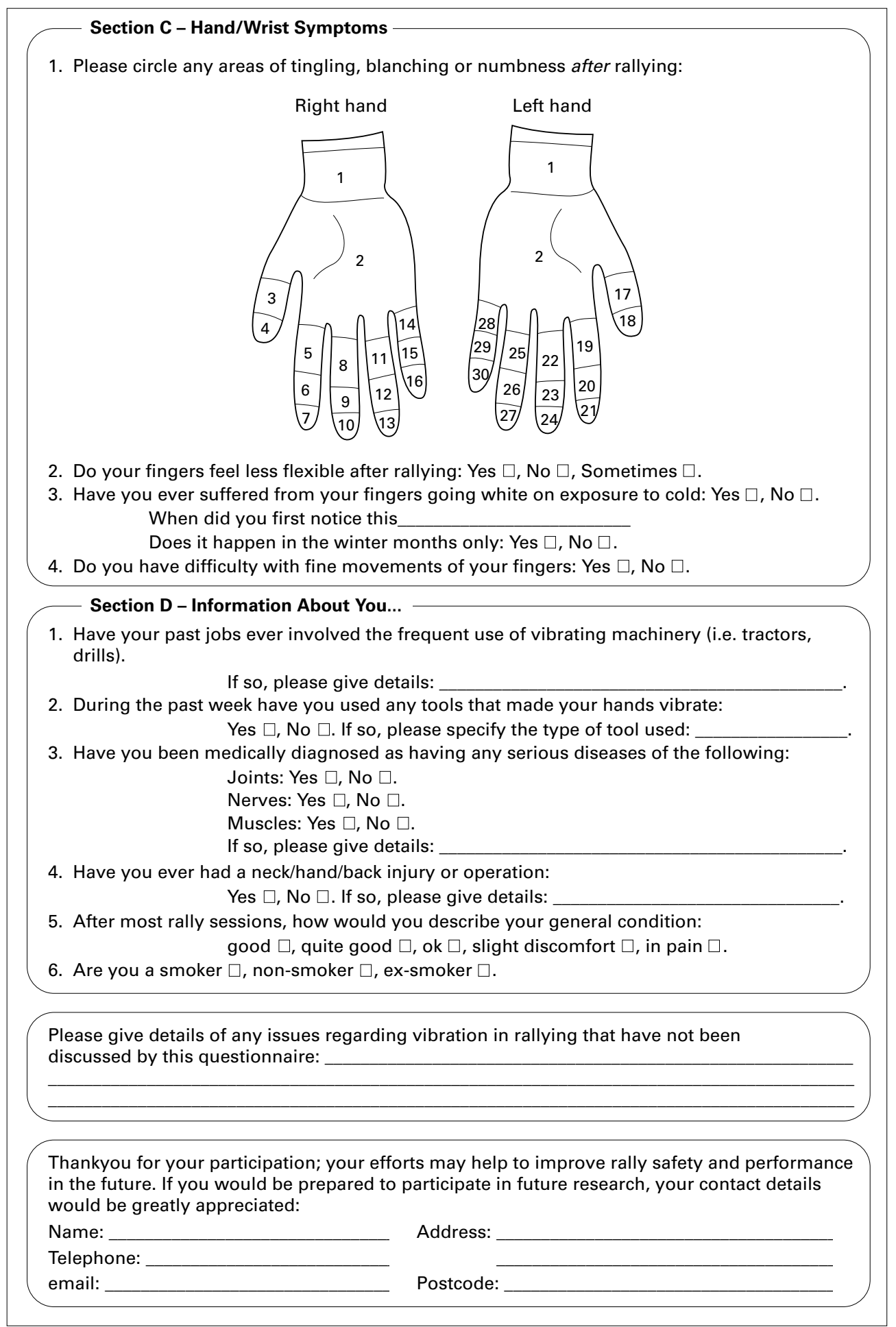

Figure 1 continued

assumed that the questionnaire may be distributed in potentially stressful environments and so a short and uncomplicated format was essential. There was therefore a compromise between the response rate and the accuracy in some of the questions.

The questionnaire was separated into four main sections (fig 1). Section A contained two questions concerned with whole body symptoms. Participants were asked to circle any areas of "pain, aching, or discomfort" felt after rallying using body maps of the front/back sections of the body. Therefore the questions on musculoskeletal symptoms were phrased such that they were directly associated with rallying, rather than point, period, or lifetime prevalences-for example, "entire life", "last 12 months" or "past week" - as used by the Nordic and MRC questionnaires. In the second question, participants were asked to indicate the degree of discomfort measured on a three point scale ("no discomfort", "some 
Table 1 Summary of sources of participants

\begin{tabular}{lll}
\hline Organisation & Means of administration & $\begin{array}{l}\text { Response } \\
\text { (number mailed) }\end{array}$ \\
\hline RAC Motor Sports Association & Postal & $14(100)$ \\
Anonymous Rally Club & Postal & $2(12)$ \\
FIA World Rally Championship & Via team doctors & $4(16)$ \\
Scottish Amateur Rally Association & Postal & $32(100)$ \\
Mobil 1 Welsh Rally & Personal administration & 53 \\
Land Rover Defender 90 Welsh Rally & Personal administration & 13 \\
Total & & 118 \\
\hline
\end{tabular}

discomfort", "considerable pain") in each of 14 regions (lower back, upper back, neck, hands and wrist, shoulders, upper arms, elbows and forearm, stomach, chest, upper legs, knees, lower leg, ankles, feet).

Section B of the questionnaire contained seven questions to classify rally experience. Although the questionnaire was only intended for stage rally drivers and co-drivers, a question to confirm the type of rallying was used to check the type of rally participation of respondents. Questions were also included to identify: whether the respondent participated as a driver, navigator, or both; the number of days of participation in rallying; for how many years the respondent had been rally driving; the posture and opinion of the seat comfort.

Section C of the questionnaire was concerned with hand and wrist symptoms. Participants were asked to circle areas of "tingling, blanching, or numbness after rallying" using a map of the front of the left and right hands. Three additional questions on flexibility of the fingers, finger blanching, and dexterity were also included.

The final section (D) posed questions about exposure to hand/arm vibration, medical condition and history, and whether the respondent was a smoker. Personal information was included at the start and end of the questionnaire. Subject sex, occupation, and date of birth were included as compulsory questions. Finally, an open section was included in which subjects were able to give details of other issues that had not been discussed in the questionnaire.

The sample consisted of 118 rally participants from the 2000 season. Most questionnaires were distributed with mailings from rally drivers' clubs or were personally administered at the 2000 Welsh Rally (table 1).

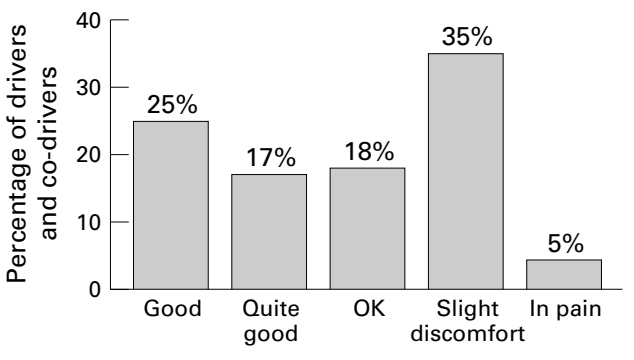

Figure 2 General condition after rallying for 90 drivers and co-drivers.

\section{Results}

GENERAL DATA

Table 2 summarises the general details of the 118 participants. "Days rallying per season" was taken as the sum of days testing and days competing. There was a large variability for the reported days rallying ranging from 0 to 350 days a year. To exclude those with minimal rally experience, all participants exposed to less than 10 days rallying per year were excluded from the subsequent analysis. Therefore data reported are for 90 rally participants who participated for more than 10 days a year. The group comprised 41 drivers, 45 co-drivers, and four who participated as both driver and co-driver. Twelve of the participants described themselves as professional rally drivers or co-drivers.

Participants were not excluded for having occupational exposure to vibrating machinery or recent exposure to vibrating tools. Much of this exposure was related to car maintenance either professionally or in preparation for the rally. Similarly, those with previous injuries or operations (29 subjects) were included in the analysis because many of these could have been rally related. Twelve had lumbar/thoracic injuries including four herniated discs and four vertebra fractures. Ten subjects reported neck injuries or whiplash. Four subjects reported broken or dislocated fingers and one had received a wrist operation.

Figure 2 summarises the reported general condition after most rally sessions: $60 \%$ of subjects felt "OK" or better; of the professionals, $82 \%$ felt "OK" or better.

In the section of the questionnaire open for other comments, four co-drivers stated that stresses on their necks were worse than for drivers; some attributed this to their lack of

Table 2 Summary data for the 118 respondents to the questionnaire

\begin{tabular}{llllllll}
\hline & $\begin{array}{l}\text { Men } \\
(n=110)\end{array}$ & $\begin{array}{l}\text { Women } \\
(n=8)\end{array}$ & $\begin{array}{l}\text { Drivers } \\
(n=49)\end{array}$ & $\begin{array}{l}\text { Co-drivers } \\
(n=61)\end{array}$ & Both $(n=8)$ & $\begin{array}{l}\text { All rally } \\
(n=118)\end{array}$ & $\begin{array}{l}>10 \text { days } \\
(n=90)\end{array}$ \\
\hline Mean (SD) age (years) & $34.4(9.9)$ & $28.4(6.0)$ & $32.1(7.5)$ & $35.4(11.5)$ & $34.6(5.7)$ & $34.0(9.7)$ & $33.4(7.7)$ \\
Smokers & 17 & 0 & 19 & 13 & 13 & 16 & 16 \\
Non-smokers & 78 & 100 & 74 & 82 & 88 & 79 & 81 \\
Ex-smokers & 6 & 0 & 6 & 5 & 0 & 5 & 3 \\
Occupational exposure & 20 & 0 & 29 & 13 & 0 & 19 & 18 \\
Recent vibration exposure & 29 & 13 & 35 & 21 & 38 & 28 & 28 \\
Neck/hand/back injury & 30 & 38 & 31 & 28 & 50 & 31 & 32 \\
Mean (SD) days rallying/season & $28(41)$ & $17(13)$ & $25(20)$ & $31(52)$ & $15(13)$ & $27(40)$ & $34(43)$ \\
Years rallying & & & & & 13 & 24 & 22 \\
$\quad<5$ & 22 & 50 & 27 & 24 & 38 & 27 & 28 \\
5-10 & 26 & 38 & 35 & 19 & 25 & 25 & 26 \\
10-15 & 27 & 0 & 27 & 24 & 25 & 23 & 24 \\
\hline 15 & 24 & 13 & 10 & 34 & 25 & \\
\hline
\end{tabular}

Values are percentages unless otherwise indicated. 


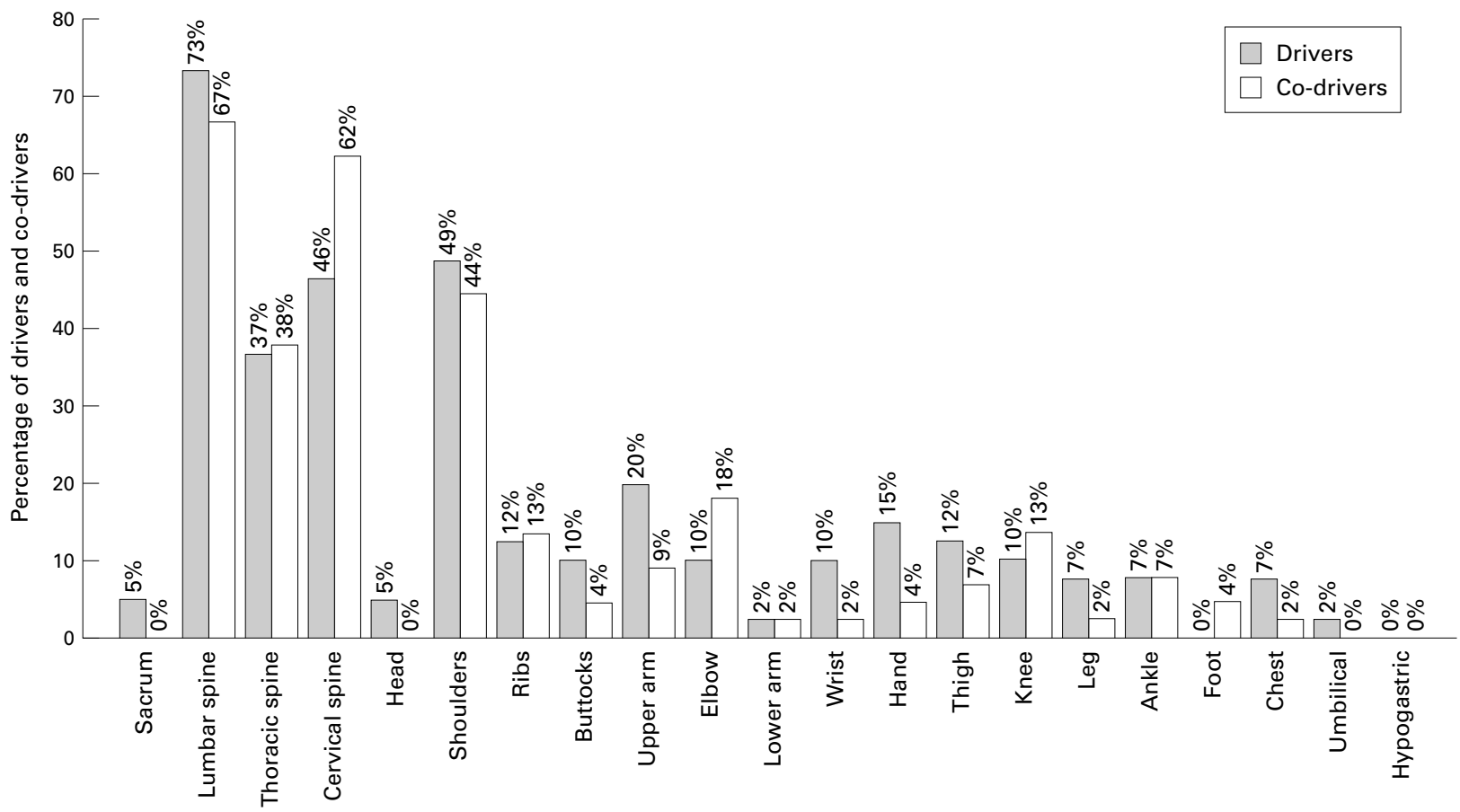

Figure 3 Prevalence of pain, aching, or discomfort after rallying for 41 drivers and 45 co-drivers.

bracing possibilities as they have no steering wheel. Two co-drivers used neck braces, and one reported a decrease in the severity of neck pain after changing to a lighter crash helmet. One co-driver noted that he would immediately feel an ache in his neck if he was looking down at his pace notes when the car hit a bump, and one driver stated that his neck and wrists would "tighten" after competitions, but the effects would wear off after three days. A driver reported that he had experienced numbness in his arms and hands and had to shake his arms mid-stage to restore feeling. Three respondents noted high noise levels. One driver had received surgery for a detached retina, which was attributed to rallying, and one co-driver complained of banging his elbows on the roll cage.

WHOLE BODY SYMPTOMS OF MUSCULOSKELETAL DISORDERS

Most (91\%) subjects with more than 10 day's annual exposure reported discomfort in at least one body area after rallying. The mean number of symptoms across the whole group was 3.20: for drivers 3.49 and for co-drivers 3.04. Almost a fifth $(18 \%)$ reported "considerable pain" in at least one area, most commonly the lumbar spine $(8 \%)$, cervical spine $(7 \%)$, and shoulders $(4 \%)$. One of the professional participants (FIA World Rally Championship co-driver) reported considerable pain in his neck after participation in rallies.

The most commonly indicated body areas in which pain, aching, or discomfort were reported were the lumbar spine $(70 \%)$, cervical spine $(54 \%)$, shoulders $(47 \%)$, and thoracic spine $(36 \%)$. Discomfort in all other regions was reported by $13 \%$ or fewer subjects. Two drivers reported pain through one arm related to cervical spine injury. Professional rally drivers and co-drivers also reported greatest discomfort in the lumbar spine (55\%), cervical spine $(73 \%)$, shoulders $(55 \%)$, and thoracic spine $(55 \%)$. Of the six professional co-drivers in the sample, five reported cervical spine discomfort after rallying.

Comparison of the reported regions of discomfort showed similar results between the drivers and co-drivers for lumbar spine, thoracic spine, and shoulders (fig 3). Reported discomfort in the cervical spine and elbow was greater for the co-drivers than for the drivers. Discomfort in the upper arm, wrist, and hand was greater for the drivers than the co-drivers.

HAND/WRIST SYMPTOMS OF MUSCULOSKELETAL DISORDERS

The prevalence of hand/wrist symptoms was lower than that for whole body symptoms. About a quarter (26\%) of respondents reported a loss of flexibility after rallying, $16 \%$ reported some blanching after cold exposure, and $8 \%$ reported difficulty with fine movements of the fingers. Some $22 \%$ circled at least one segment on the hand map showing areas of tingling, blanching, or numbness after rallying. Drivers were more likely to report a loss of flexibility than co-drivers $(37 \%$ v $11 \%)$, and $32 \%$ of drivers circled at least one segment on the hand map compared with $9 \%$ of co-drivers. Drivers and co-drivers circled an average of 1.29 and 0.29 areas of tingling, blanching, or numbness respectively.

Tingling, blanching, or numbness after rallying was most common in the palms of either hand and in the proximal phalanx of the left index finger. Problems were least common in the distal phalanges of both hands. One female subject who competed as both a driver and co-driver reported tingling, blanching, or numbness in all phalanges of the fingers (not thumbs). She accounted for all but two of the 


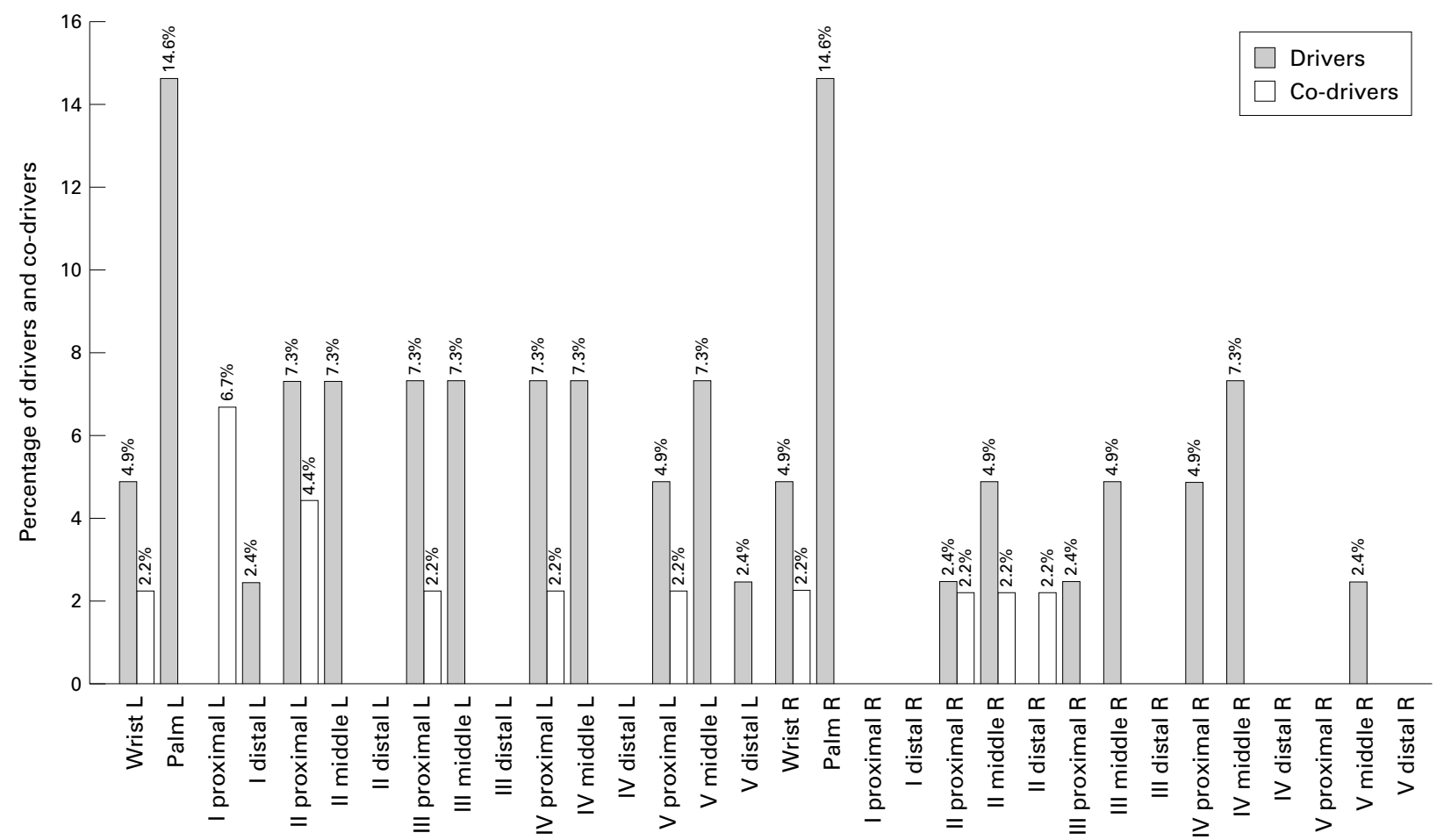

Figure 4 Prevalence of hand tingling, blanching, or numbness after rallying for 41 drivers and 45 co-drivers.

reported incidences of tingling, blanching, or numbness in the distal phalanges.

No co-drivers reported problems in their palms, despite this being the most common region reported by the drivers, and only one co-driver reported problems in each wrist (fig 4). The incidence of tingling, blanching, or numbness was higher for drivers in all regions except for the proximal phalanx of the left thumb and the distal phalanx of the right index finger.

\section{Discussion}

The results generally support the initial hypotheses: there appears to be a high prevalence of symptoms of whole body musculoskeletal disorders among all rally participants and more hand and wrist symptoms were reported by drivers than co-drivers. The most commonly reported symptoms consisted of discomfort in the lumbar, thoracic, and cervical spine and shoulders, and loss of dexterity in the hands.

Most subjects experience some degree of discomfort after competing. Some subjects reported considerable pain, yet this was not deemed to outweigh the benefits of participating in rallies. It is assumed that those drivers and co-drivers who experienced intolerable pain would decide to stop rallying, and therefore one may assume that this group of current rally participants excludes those with the most severe pain. Notwithstanding this, some drivers who reported discomfort also described simultaneous feelings of excitement and elation after rallying. Therefore the "healthy worker" effect previously described may be somewhat diluted for leisure activities when compared with occupational disorders.

This study found a prevalence of pain, aching, or discomfort in the lumbar spine of
$70 \%$ for respondents who rally for more than 10 days per year. This is lower than the $89 \% 12$ month period incidence of low back pain in rally drivers reported by Videman et $a l .{ }^{4}$ The study of F1 drivers by Burton and Sandover ${ }^{3}$ found a higher prevalence of lumbar pain (93\%) and cervical pain (67\%) than reported here $(70 \%$ and $54 \%$ respectively).

Most previous surveys of musculoskeletal disorders have been carried out on subjects exposed to occupational physical stresses. For drivers of standard and off-road vehicles, exposure to high magnitudes of vibration and mechanical shock has been suggested to contribute to musculoskeletal disorders. ${ }^{10} 11$ Bovenzi and Hulshof ${ }^{12}$ reviewed low back pain attributed to exposure to whole body vibration in 17 studies which also included a control group. Of these, 12 reported prevalence of low back pain for a total of 3430 people exposed to high magnitudes of whole body vibration in a variety of occupations, including 1705 tractor drivers, 492 train drivers, and 402 fork lift truck drivers. The prevalence of low back pain averaged across all "exposed" subjects was $58 \%$ (based on the " 1 year" or "regular" prevalences). The same 12 studies reported control data for 1291 subjects. Porter et $a l^{13}$ reported low back discomfort for 1000 standard road car drivers, who could be considered as comparable with the control groups in the review of Bovenzi and Hulshof. Combining these two data sets, the prevalence of low back pain averaged across all 2291 "non exposed" subjects was $29 \%$. This study therefore indicates a higher prevalence of pain, aching, or discomfort in the lumbar spine for rally drivers and co-drivers than either the general population or those employed in industries where exposure to whole body vibration is considered 
a problem. However, one must be cautious in comparing previously reported data with this study as many of the questionnaires in the literature were administered in different languages and with different wording, although most were based on the Nordic design.

The view of some respondents that neck pain was more common for co-drivers was confirmed in the questionnaire results. However, the higher prevalence of cervical spine discomfort for co-drivers $(62 \%)$ than drivers $(46 \%)$ was not significant $\left(\chi^{2}, \mathrm{p}>0.05\right)$.

As expected, there were significantly more reported hand/wrist symptoms for drivers than co-drivers $(p<0.01$, Mann-Whitney). There was also a significant loss of flexibility for drivers compared with co-drivers after competing $\left(\chi^{2}, \mathrm{p}<0.01\right)$. It is logical to attribute these findings to drivers gripping the steering wheel and co-drivers having no external force input to the hands. One may therefore expect to find symptoms of hand and wrist injury in drivers in other forms of motorsport. Some $59 \%$ of drivers reported some type of hand and wrist symptom - that is, positive response in any part of section $\mathrm{C}$ of the questionnaire-which is comparable to the $64 \%$ prevalence of hand or wrist problems in $\mathrm{F} 1$ drivers. ${ }^{1}$ This study does not indicate that vibration of a rally car steering wheel causes vibration white finger, as there were minimal reports of problems with distal phalanges of the digits, where the condition usually originates.

It is hypothesised that exposure to vibration in rally cars is higher than in most industrial environments, but that exposure times are shorter. If acceleration at the seat was known, then the total annual exposure could be estimated and compared with other industries where dose-effect relations have been suggested.

CONCLUSIONS

Most stage rally participants report symptoms of musculoskeletal disorders: $70 \%$ of all participants reported discomfort in the lumbar spine, and $54 \%$ of participants reported discomfort in the cervical spine. Drivers have more symptoms of hand and wrist injury than co-drivers. The prevalence of musculoskeletal injury in rally drivers and co-drivers is greater than that reported for many industrial workers. Future work should focus on identifying the extent of vibration exposure in motorsport.

We are grateful to the RAC Motor Sports Association, Scottish Amateur Rally Association, FIA World Rally Championship teams, and Mobil 1 British Rally Championship for their assistance and cooperation with this study.

1 Masmejean EH, Chavane $\mathrm{H}$, Chantegret A, et al. The wrist of the formula 1 driver. Br f Sports Med 1999;33:270-3.

2 Howes C. Wrist injuries in sport. Sports Med 1994;3:16375.

3 Burton AK, Sandover J. Back pain in Grand Prix drivers: a 'found' experiment. Appl Ergon 1987;18:3-8.

4 Videman T, Simonen R, Usenius JP, et al. The long-term effects of rally driving on spinal pathology. Clin Biomech 2000;15:83-6.

5 Battié MC, Videman T, Gibbons LE, et al. Determinants of lumbar disc degeneration: a study relating lifelong exposures and magnetic resonance imaging findings in identical wins. Spine 1995;20:2601-12.

6 Brinckmann P, Frobin W, Biggemann M, et al. Quantification of overload injuries to thoracolumbar vertebrae and discs in persons exposed to heavy physical exertions or vibration at the workplace. Part 2. Occurrence and magnitude of overload injury in exposed cohorts. Clin Biomech 1998;13(suppl 2):S(2)1-36.

7 Kuorinka I, Jonsson B, Kilbom A, et al. Standardised Nordic questionnaires for the analysis of musculoskeletal symptoms. Appl Ergon 1987;18:233-7.

8 Magnusson ML, Pope MH, Hulshof CTJ, et al. Development of a protocol for epidemiological studies of whole-body vibration and musculoskeletal disorders of the lower back. Fournal of Sound and Vibration 1998;215:64352.

Palmer KT, Coggon D, Pannett B, et al. The development of a self-administered questionnaire to assess exposures to hand-transmitted and whole-body vibration and their health effects. Fournal of Sound and Vibration 1998;215: $653-86$.

10 Kjellberg A, Wikström B-O, Landström U. Injuries and other adverse effects of occupational exposure to wholebody vibration: a review for criteria documentation. Arbete och Hälsa vetenskaplig skriftserie $1994 ; 41$.

11 Lings S, Leboeuf-Yde, C. Whole-body vibration and low back pain: a systematic, critical review of the epidemiological literature 1992-1999. Int Arch Occup Environ Health 2000;73:290-7.

12 Bovenzi M, Hulshof CTJ. An updated review of epidemiologic studies on the relationship between exposure to whole-body vibration and low back pain. Fournal of Sound and Vibration 1998:215:595-612.

13 Porter JM, Porter CS, Lee VJA. A survey of driver discomfort. In: Lovesley EJ, ed. Contemporary ergonomics. London: Taylor and Francis, 1992:262-7.

\section{Take home message}

This questionnaire study shows a high prevalence (70\%) of low back pain and discomfort in rally drivers and co-drivers after competition. More discomfort in the cervical spine was reported by co-drivers (62\%) than drivers (46\%), possibly because of the lack of bracing opportunities. Conversely, more discomfort in the hands and wrists was reported by drivers $(32 \%)$ than co-drivers $(9 \%)$ probably because of the forces from the steering wheel. 